\title{
Impact of Universal Health Coverage on Child Growth and Nutrition in Argentina
}

Pablo A. Nuñez, PhD, Diego Fernández-Slezak, PhD, Andrés Farall, MSc, María Eugenia Szretter, MSc, Oscar Daniel Salomón, PhD, and

Claudia R. Valeggia, PhD

Objectives. To estimate trends of undernutrition (stunting and underweight) among children younger than 5 years covered by the universal health coverage programs Plan Nacer and Programa Sumar.

Methods. From 2005 to 2013, Plan Nacer and Programa Sumar collected high-quality information on birth and visit dates, age (in days), gender, weight (in $\mathrm{kg}$ ), and height (in $\mathrm{cm}$ ) for 1.4 million children in 6386 health centers (13 million records) with broad coverage of vulnerable populations in Argentina.

Results. The prevalence of stunting and underweight decreased $45.0 \%$ (from 20.6\% to $11.3 \%$ ) and $38.0 \%$ (from $4.0 \%$ to $2.5 \%$ ), respectively, with differences between rural versus urban areas, gender, regions, age, and seasons.

Conclusions. Undernutrition prevalence substantially decreased in 2 programs in Argentina as a result of universal health coverage. (Am J Public Health. 2016;106:720726. doi:10.2105/AJPH.2016.303056)

See also Galea and Vaughan, p. 592.

$\mathbf{U}$ nequal access to health care, inadequate nutrition, and higher levels of exposure to infections are the major causes of disparities in morbidity and mortality in children. ${ }^{1,2}$ Inequalities in early life are expressed as restricted growth (stunting) and underweight, which not only impair children's development physically, cognitively, socially, and emotionally but also lead to poorer educational and economic outcomes later in life. ${ }^{3-5}$ Stunting has been considered the best proxy for child health inequalities because it reflects cumulative linear growth faltering during the prenatal period and the first years of life. ${ }^{6}$

During the past decade, most Latin American countries implemented innovative programs to improve population health outcomes and to reduce inequalities in health access focusing on universal health coverage (UHC) for vulnerable populations. ${ }^{7,8}$ Faced with deteriorating health indicators, in October 2004 Argentina's government implemented Plan Nacer to strengthen a fragmented national health system plagued by strong jurisdictional asymmetries after the 2001 economic crisis. The program introduced innovative changes in the incentive framework of health care providers to equitably increase the access and quality of prioritized health services for pregnant women and children younger than 5 years. ${ }^{9,10}$

Moving forward toward effective UHC, the follow-up program Programa Sumar was launched in 2013, expanding the strategy and extending health care coverage to 5.7 million children and adolescents (0-19 years) and 3.8 million women younger than 64 years. Both programs were implemented synergistically with the main conditional cash transfer programs Asignación Universal por Hijo and Asignación Universal por Embarazo. ${ }^{11}$ Under both conditional cash transfer programs, the enrollment of beneficiaries in the UHC programs is a requisite that increases development options of vulnerable families and promotes preventive health care,

\section{ABOUT THE AUTHORS} New Haven, CT clicking the "Reprints" link.

This article was accepted December 17, 2015.

doi: 10.2105/AJPH.2016.303056 nutrition, and education (more details available as a supplement to the online version of this article at http://www.ajph.org as Text S1).

Several studies assessed the effects of UHC strategies coupled to conditional cash transfer programs introduced by Latin American countries. Improvements in anthropometric measures of growth and health statuses in children younger than 5 years were observed after the implementation of Bolsa de Familia in Brazil, ${ }^{12}$ Oportunidades in Mexico, ${ }^{13}$ and Familias en Acción in Colombia, ${ }^{14}$ along with varied results in other countries. ${ }^{7,15-17}$ Plan Nacer and Programa Sumar achieved significant improvements in birth outcomes by reducing the risk of neonatal death and increasing birth weight and contributed to a $22 \%$ reduction in infant mortality and a $10 \%$ reduction in maternal mortality between 2005 and 2012. ${ }^{10,18}$ However, the outcome of these program implementations on the prevalence of undernutrition has not been analyzed before.

We analyzed trends for the prevalence of stunting and underweight among the overall population of children younger than 5 years, who were beneficiaries of the UHC programs Plan Nacer and Programa Sumar during the 9-year period since their implementation (2005-2013). We assessed the impact of the programs' implementation and contributed to developing a statistical model that generates updated population-based information to follow health progress on and challenges to child growth and development issues.

Pablo A. Nuñez and Oscar Daniel Salomón are with the Instituto Nacional de Medicina Tropical, Misiones and CONICET. Diego Fernández-Slezak is with the Laboratorio de Inteligencia Artificial Aplicada, Universidad de Buenos Aires, Buenos Aires, Argentina. Andrés Farall is with Ecoclimasol, Buenos Aires. María Eugenia Szretter is with the Departamento de Matemáticas e Instituto del Cálculo, Universidad de Buenos Aires. Claudia R. Valeggia is with the Department of Anthropology, Yale University,

Correspondence should be sent to Pablo A. Nuñez, PhD, Instituto Nacional de Medicina Tropical (INMeT), Neuquén y Jujuy s/n (3370), Puerto Iguazú, Misiones, Argentina (e-mail: pb.nunez@gmail.com). Reprints can be ordered at http://www.ajph.org by 


\section{METHODS}

We estimated trends of stunting and underweight between 2005 and 2013 on the basis of the distribution of height for age (HAZ) and weight for age (WAZ) for children younger than 5 years covered by the UHC programs Plan Nacer (2005-2012) and Programa Sumar (2013-2016).

\section{Data Processing}

During the 9-year period, according to UHC program operations, Plan Nacer and Programa Sumar collected more than 13 million records in 6386 health centers during routine check-ups that were part of the program (data available as a supplement to the online version of this article at http:// www.ajph.org as Figure S1 and Text S2). The collected information included several objectives that are forwarded every 4 months to the Argentina Ministry of Health. The flow of data allowed us to centralize a very large volume of high-quality information and provided very broad coverage and representativeness of the target population.

Analyzed data for each record consists of an anonymous identifier for each individual, geographical source, the rural versus urban area from which the record comes, and the variables used to calculate $z$-scores: birth and visit dates, age (in days), gender, weight (in kg) and height (in cm; data available as a supplement to the online version of this article at http://www.ajph.org as Figure S1). We designed a relational database for storing this information in multiple tables, which significantly reduced the amount of redundant information.

In the first wave of data clean-up, we removed approximately $13 \%$ of the records for further analysis (criteria used is available in a supplement to the online version of this article at http://www.ajph.orgin as Text S2). We used the same database system to upload the World Health Organization 2007 standards tables, ${ }^{19}$ which we used to calculate $z$-scores from stored data. On the basis of the available individual-level data for each record (age, weight, and height at each visit and gender) and the gender-specific World Health Organization growth standards, we calculated $z$-scores using the LMS method. ${ }^{20}$ After we calculated $z$-score values, we excluded outlier values (i.e., those that were biologically implausible; approximately $1 \%$; data available as a supplement to the online version of this article at http://www.ajph.org as Figure S1 and Text S2). Using Structured Query Language queries, we extracted different cuts of the database for posterior analysis.

\section{Statistical Analysis}

We defined the prevalence of stunting and severe stunting (for HAZ) and of underweight and severe underweight (for WAZ) as the proportion of children who fell below an SD of -2 and an SD of -3 , respectively. We applied linear mixed effects regression models to estimate trends for the prevalence of stunting, severe stunting, underweight, and severe underweight over the 9-year program implementation period.

In this setting, where we have the whole population data set of the beneficiaries of Plan Nacer and Programa Sumar (except for those we were unable to use because of missing data), the relevance of proposing and fitting a statistical model is not the inference of unknown parameters, but the ability of the model to summarize the global behavior of the prevalence throughout the years of interest, across the regions, and for each gender, age, or urban versus rural residence, highlighting the central trends and patterns. Also, the use of a statistical model allows us to avoid potential bias effects in the analysis that result from imbalanced interactions of the variables influencing the prevalence calculations.

An example of this imbalance (which comes from the observational nature of the study), is the distribution of ages of the children included in the study. (The boxplots of age for year of control, in which it is apparent that during the first years of the programs [2005-2006] younger than average children were included, are available as a supplement to the online version of this article at http://www.ajph.org as Text S3.) Stunting and underweight are related to age; an empirical plot of the prevalence versus control year would show trends resulting from this imbalance.

Moreover, different health centers (within departments and provinces) were enrolled in the study at different times (data available as a supplement to the online version of this article at http://www.ajph.org as Figures
S3-S5), which could bias the estimate for prevalence at the national level because the prevalence levels of the children receiving health care at these centers are expected to differ considerably. For instance, if health centers with higher prevalence had joined the study in earlier stages than had centers with lower prevalence, the temporal trend would show an artificial decrease in prevalence at the national level even if the true prevalence was constant. Thus, the model should take into account this important feature to control any potential bias.

Although the majority of beneficiaries remained in the same health center throughout the period of interest (from birth or study enrollment until age 5 years), 18.3\% crossed over, at least once, between health centers over the course of the study. Thus, we included beneficiary identification in the model as a random effect, which also addresses the problem imposed by the presence of repeated measurements of most children in our database. It is worth stressing that the mentioned cross-over between centers precludes the use of any kind of nesting in the model. Moreover, because undernutrition is a child's, not a center's, attribute, once the beneficiary effect is taken into account there is no need to include a health center effect (fixed or random) in the model.

After some exploratory data analysis, we selected a linear mixed effect model (data available as a supplement to the online version of this article at http://www.ajph.org as Text S4) to explain the trends of undernutrition prevalence. The model included the beneficiary identification as a random effect and the date (month and year of the health check-up of the beneficiary), age (in days), rural versus urban setting (describing the health center area), and gender as fixed effects. (Details of the model and equations are described in a supplement to the online version of this article at http://www.ajph.org as Text S4.)

To model probabilities (in this case, prevalence), it is customary to use a generalized linear mixed effect model, ${ }^{21}$ the most widely used being the logistic regression (mixed effect) model. This model takes into account the natural heteroscedasticity of a Bernoulli variable, that is, a stunted versus not stunted variable, and guarantees that the estimated probabilities lie in the $(0,1)$ 
interval. However, because of the size of the data set ( $>10$ million records), the consistency property of a more simple estimation procedure on the basis of a linear mixed effect model guarantees the convergence of the estimates to the true parameter values (prevalence) under the stated model; thus a more complex generalized model is not justified in this case. Furthermore, the added complexity of the estimation procedure of a generalized model through an approximate likelihood function leads to more computationally intensive estimation algorithms, which was not justified in this case.

We estimated model A (data available as a supplement to the online version of this article at http://www.ajph.org as Text S4) with R 3.1.3, ${ }^{22}$ through library lme $4 .^{23}$ The algorithm we used to fit the linear mixed effects models optimizes the restricted (or residual) maximum likelihood criterion. As reported by Pinheiro, ${ }^{24}$ the restricted (or residual) maximum likelihood estimates in a linear mixed effects model are consistent and asymptotically normal. Because of this, and taking into account the size of our database, we chose a linear model that considers the dependence of the data through the mixed effect terms over a nonlinear model that is hard to fit with this huge number of cases. A thorough description of mixed models can be found in Pinheiro and Bates. ${ }^{25}$

To test the adequacy of the linear mixed effects model in this setting, we conducted several simulation experiments with the same data structure as our original database, which supported the accuracy and effectiveness of our proposed approach.

\section{RESULTS}

We processed more than 10 million records, which corresponded to 1404631 children younger than 5 years, that were collected in 6386 health centers during the 9-year period (data available as a supplement to the online version of this article at http:// www.ajph.org as Figures S1-S2 and Table S1). Twenty-six percent (365 204) of the beneficiaries contributed a unique measure, 14.0\% (196648) contributed 2 repeated measures, and $60.0 \%$ (842 779) contributed 3 or more repeated measures. The median of the records distribution was 4 repeated measures by beneficiary.

The Plan Nacer was first implemented (2005-2006) in 9 provinces in northwestern (NOA) and northeastern (NEA) Argentina, which historically have experienced the highest levels of maternal and child mortality and have a higher proportion of vulnerable persons. These 2 years account for less than $3 \%$ of the total data. In 2007 , the program was expanded to cover the rest of the country (data available as a supplement to the online version of this article at http://www.ajph.org as Figure S2). In 2010, it was operating in almost the whole country, covering a target population of approximately $16 \%$ of all children younger than 5 years in the country.

We observed higher coverage levels in NOA and NEA regions, with more than $40 \%$ of the total child population covered (data available as a supplement to the online version of this article at http://www.ajph.org as Figure S2). Since Plan Nacer's implementation, each province (and each department and health center) was gradually incorporated. Therefore, each level showed heterogeneous exposure during the overall period for the percentage of coverage and for the amount of collected information (data available as a supplement to the online version of this article at http://www.ajph.org as Figures

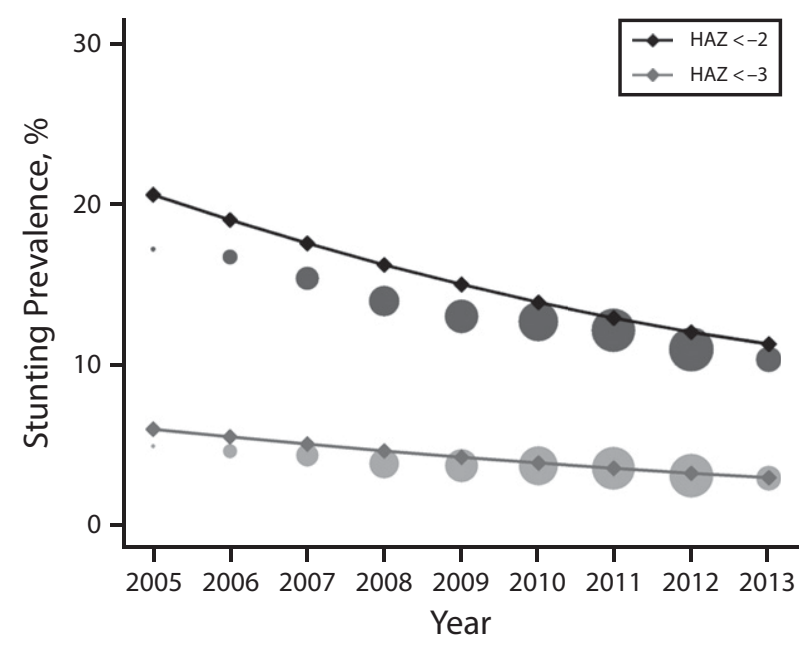

Note. HAZ = height-for-age $z$-score. We estimated prevalence of stunting (HAZ <-2) and severe stunting $(\mathrm{HAZ}<-3)$ for the whole population using linear mixed effects (LME) model A (solid line) to the whole data set and then conditioning to the mean (observed) values of gender, urban vs rural residence, and age. Circles represent empirical proportions, with the total area proportional to the number of records in the year.

FIGURE 1-Estimated Trends and Empirical Stunting Prevalence in Children Younger Than 5 Years Covered by the Universal Health Coverage Programs: Argentina, 2005-2013 
TABLE 1-Estimated Prevalence of Undernutrition in Children Younger Than 5 Years Covered by the Universal Health Coverage Programs: Argentina, 2005-2013

\begin{tabular}{|c|c|c|c|c|c|c|c|c|c|}
\hline Population & 2005 & 2006 & 2007 & 2008 & 2009 & 2010 & 2011 & 2012 & 2013 \\
\hline \multicolumn{10}{|c|}{$\%$ Stunting per year (HAZ $<-2)$} \\
\hline \multicolumn{10}{|l|}{ National } \\
\hline Total & 20.6 & 19.0 & 17.5 & 16.2 & 15.0 & 13.9 & 12.9 & 12.0 & 11.3 \\
\hline Urban & 20.4 & 18.8 & 17.4 & 16.0 & 14.8 & 13.7 & 12.7 & 11.9 & 11.1 \\
\hline Rural & 23.0 & 21.4 & 20.0 & 18.6 & 17.4 & 16.3 & 15.3 & 14.4 & 13.7 \\
\hline Boys & 22.0 & 20.4 & 18.9 & 17.6 & 16.4 & 15.3 & 14.3 & 13.4 & 12.7 \\
\hline Girls & 19.2 & 17.6 & 16.2 & 14.8 & 13.6 & 12.5 & 11.5 & 10.7 & 9.9 \\
\hline \multicolumn{10}{|l|}{ Region } \\
\hline NOA & 17.8 & 16.6 & 15.5 & 14.5 & 13.5 & 12.6 & 11.7 & 10.9 & 10.2 \\
\hline NEA & 21.0 & 20.0 & 18.9 & 17.9 & 16.9 & 15.9 & 14.9 & 14.0 & 13.1 \\
\hline Centro & & & 14.2 & 14.3 & 14.1 & 13.9 & 13.4 & 12.8 & 12.1 \\
\hline Cuyo & & & 16.9 & 15.6 & 14.4 & 13.3 & 12.3 & 11.3 & 10.5 \\
\hline Patagonia & & & 13.3 & 12.1 & 11.0 & 10.1 & 9.4 & 8.9 & 8.7 \\
\hline \multicolumn{10}{|c|}{$\%$ Underweight per year (WAZ <-2) } \\
\hline \multicolumn{10}{|l|}{ National } \\
\hline Total & 4.0 & 3.9 & 3.9 & 3.8 & 3.6 & 3.4 & 3.1 & 2.8 & 2.5 \\
\hline Urban & 4.0 & 4.0 & 3.9 & 3.8 & 3.6 & 3.4 & 3.2 & 2.8 & 2.5 \\
\hline Rural & 3.9 & 3.9 & 3.8 & 3.7 & 3.5 & 3.3 & 3.1 & 2.7 & 2.4 \\
\hline Boys & 4.3 & 4.3 & 4.3 & 4.2 & 4.0 & 3.8 & 3.5 & 3.2 & 2.8 \\
\hline Girls & 3.6 & 3.6 & 3.5 & 3.4 & 3.2 & 3.0 & 2.8 & 2.5 & 2.1 \\
\hline \multicolumn{10}{|l|}{ Region } \\
\hline NOA & 3.3 & 3.1 & 3.0 & 2.8 & 2.7 & 2.5 & 2.3 & 2.1 & 1.9 \\
\hline NEA & 5.0 & 4.8 & 4.5 & 4.3 & 4.0 & 3.7 & 3.3 & 3.0 & 2.6 \\
\hline Centro & & & 9.7 & 8.0 & 6.6 & 5.3 & 4.2 & 3.2 & 2.4 \\
\hline Cuyo & & & 6.2 & 5.2 & 4.3 & 3.6 & 3.0 & 2.5 & 2.2 \\
\hline Patagonia & & & 7.7 & 6.0 & 4.5 & 3.5 & 2.8 & 2.5 & 2.5 \\
\hline
\end{tabular}

Note. $\mathrm{HAZ}=$ height-for-age $z$-score; LME = linear mixed effects; NEA = northeast Argentina; $\mathrm{NOA}=$ northwest Argentina; WAZ = weight-for-age $z$-score. We estimated the prevalence of stunting and underweight fitting LME model $A$ to the whole data set and then conditioning to the mean (observed) values of gender, urban vs rural residence, and age (national), gender and age (for urban and rural), urban vs rural residence, and age (for boys and girls). For regions, we fitted the model splitting the database by region and then conditioning on mean values of gender, urban vs rural residence, and age.

Figure S6). Severe stunting also showed a highly significant relative decrease of almost 50\%, from 6\% in 2005 to 3\% in 2013 (Figure 1). Trends for severe stunting between rural and urban areas, gender, and regions followed the same patterns as stunting (data available as a supplement to the online version of this article at http://www.ajph.org as Figure S8 and Table S2).

\section{Underweight}

The prevalence of underweight decreased from $4.0 \%$ to $2.5 \%$, representing a relative decrease of $38.0 \%$ during the 9 -year period (Figure 2; Table 1). Unlike in the case of stunting prevalence, we observed no differences between rural and urban areas; however, differences by gender remained consistent with the higher prevalence of underweight we observed for boys than we observed for girls (Table 1; data available as a supplement to the online version of this article at http://www.ajph.org as Figure S7).

The 5 regions showed significant decreasing trends with varying slopes and relative decrease rates that ranged from 75\% in Centro to $42 \%$ in NOA (Table 1; data available as a supplement to the online version of this article at http://www.ajph.org as Figure S7). Severe underweight also displayed decreasing trends in all subpopulations analyzed, consistent with results obtained for underweight (Figure 2; data available as a supplement to the online version of this article at http://www.ajph.org as Figure S9 and Table S3).

\section{Age and Seasonal Variations}

We modeled the prevalence of stunting and underweight with age and analyzed the empirical prevalence, the mean HAZ value, and height for age difference, which has been proposed as a complementary and accurate indicator at all ages. ${ }^{26,27}$ The prevalence of stunting showed decreasing trends with age, starting with higher values, and declined in the first 6 months. We observed a pronounced increase in stunting among children aged between 6 and 18 months, after which we observed a continuous decreasing trend with age. Interestingly, the distribution of stunting exhibited significant improvements in all ages, with descending curves of timing of growth faltering during the 9-year period (Figure 3a; data available as a supplement to the online version of this article at http://www.ajph.org as Figure S10).

The prevalence of underweight rapidly decayed with age during the first 12 months of life and then remained relatively constant (Figure 3b; data available as a supplement to the online version of this article at http:// www.ajph.org as Figure S10). We observed significant differences for the different years with decreasing prevalence, mostly starting in 2010. We observed similar patterns when we analyzed the mean HAZ, WAZ, and height for age difference values (data available as a supplement to the online version of this article at http://www.ajph.org as Figure S11).

We observed a clear seasonality effect in the magnitude of child undernutrition prevalence. We observed a peak in the prevalence of stunting during the months of the cold season (July to August), whereas for underweight we observed a peak during the hot season (December to February).

We found a negative correlation between the 2 outcomes (data available as a supplement to the online version of this article at http:// www.ajph.org as Figure S12).

\section{DISCUSSION}

Undernutrition underlies $45 \%$ of deaths among children younger than 5 years. ${ }^{4}$ It 


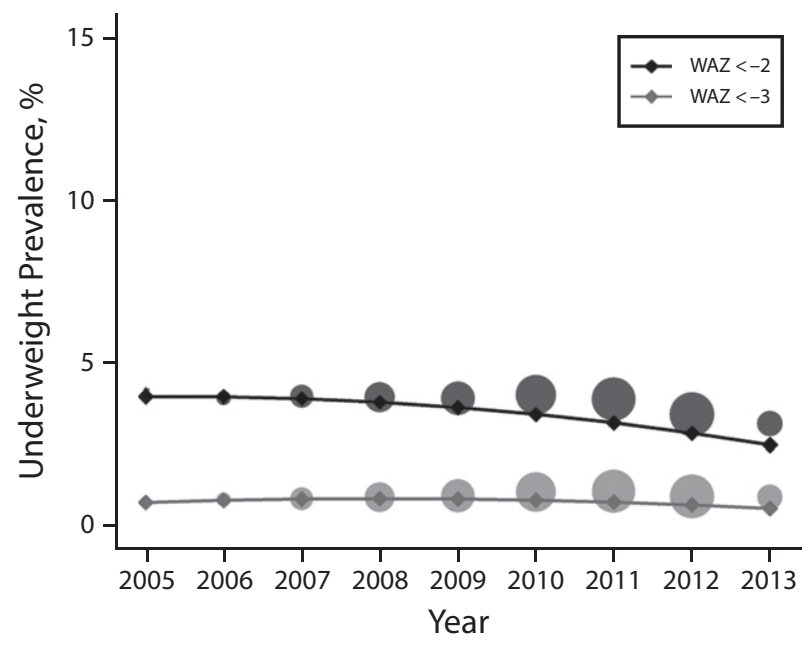

Note. WAZ = weight-for-age $z$-score. We estimated prevalence of underweight (WAZ <-2) and severe underweight (WAZ <-3) for the whole population using linear mixed effects (LME) model A (solid line) to the whole data set and then conditioning to the mean (observed) values of gender, urban vs rural residence, and age. Circles represent empirical proportions, with the total area proportional to the number of records in the year.

FIGURE 2-Estimated Trends and Empirical Underweight Prevalence in Children Younger Than 5 Years Covered by the Universal Health Coverage Programs: Argentina, 2005-2013

should be noted that mortality, because of its visibility and severity, is only the "tip of the iceberg" of malnutrition. Stunting, because of its high prevalence and long-term effects on child development, should be considered the best marker of child health disparities. ${ }^{5}$ As a major global health issue, stunting takes precedence because it pervasively affects the developmental potential of individuals and, collectively, societies. ${ }^{28}$ Although health care reforms have led to a global decline in the prevalence of stunting in the past decades, progress has been uneven across countries and regions in the world. ${ }^{29,30}$

Our findings describe a substantial decrease in the prevalence of stunting and underweight among children covered by UHC programs in Argentina between 2005 and 2013.

Findings are representative of only this target population, who are substantially more vulnerable to undernutrition than is the general Argentine child population. Although deeply rooted in poverty, stunting is a phenomenon influenced by a wide range of social health determinants. ${ }^{1,5}$ The observed improvement in children's nutritional status was probably owing to more than the implementation of UHC and conditional cash transfer programs.

In the past decade, the Argentine economy showed a period of sustained growth and underwent significant social progress. $\mathrm{Na}$ tional public spending was directed in ways meant to bring huge benefits to citizens, with the aim of greatly decreasing poverty and indigence, improving the functional distribution of income, increasing the employment rate, and fostering the access to clean water, hygiene, and sanitation. Also, a free public immunization program with 19 vaccines was conducted, among other reforms. ${ }^{31,32}$ This overhaul in public programming was associated with a $27.0 \%$ reduction in the infant mortality rate $(14.3-10.8$ per 1000$)$ and a

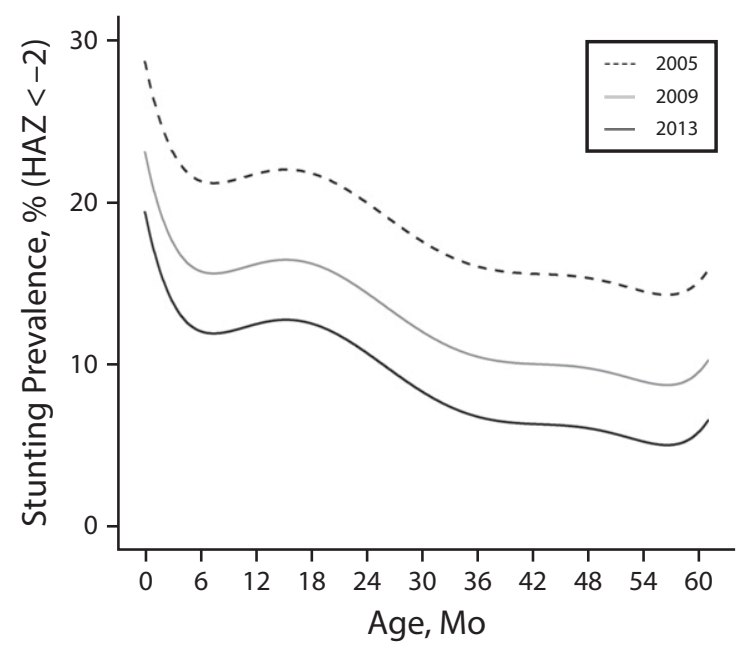

b

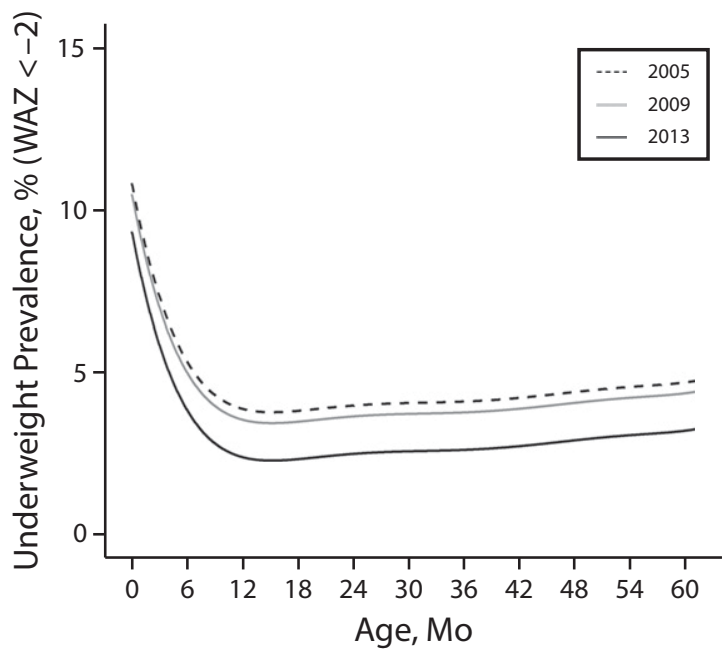

Note. $\mathrm{HAZ}$ = height-for-age $z$-score; $\mathrm{WAZ}=$ weight-for-age $z$-score 
a $17.0 \%$ reduction in the maternal mortality rate (3.9-3.2 per 10000 ) between 2005 and $2013 .^{18}$

Other successful, longer-running UHC programs in Latin America created significant improvements in the decline of undernutrition prevalence. In Brazil, stunting decreased from $37.0 \%$ to $7.0 \%$ between 1974 and 2007 following the universalization of health care coverage through the Bolsa de Familia program, together with socioeconomic and demographic improvements. ${ }^{33,34}$ Similarly, the Oportunidades program was associated with lower prevalence of stunting in Mexico, ${ }^{13}$ which decreased from $27.0 \%$ to 16.0\% between 1988 and 2006 because of targeting and coverage of conditional cash transfer and universal health access, ${ }^{35}$ among other things with varied results in different countries. $^{7,15-17}$

Substantial evidence highlights a marked disparity in the prevalence of nutritional deficiencies between rural populations and their urban counterparts. ${ }^{36-38}$ Moreover, higher rates of obesity combined with a persistently high prevalence of stunting and a lower prevalence of underweight were associated with rapid nutritional transition in developing countries. ${ }^{21}$ We observed decreasing trends in the prevalence of stunting and severe stunting in both rural and urban populations. However, rural populations maintained a higher prevalence of stunting and obesity (data not shown), requiring the commitment to continue improving development indicators in rural areas.

Our results show decreasing trends for the prevalence of stunting and underweight in the 5 regions. We found significant differences between regions at the starting points but a significant closing gap between them over the years, reducing disparities across the country. We observed that seasonality shaped temporal growth patterns, creating fluctuations in the prevalence of child undernutrition. The underlying causes may be related to frequent infections with strong seasonality that might lead to linear growth failure and to underweight, for example, acute respiratory infections (which are more prevalent during cold seasons) and diarrheal diseases (which are more prevalent during hot or rainy seasons). Moreover, a wide range of factors, including the month of birth, food availability, rainfall patterns affecting the production cycle, and nutrition intake, should be considered. Understanding how health risks change as a result of seasonal variations is likely to become of increasing importance in the context of climate change.

As has been extensively reported, stunting varies widely with age and principally influences the "1000-days" window of opportunity, which begins in utero and continues for (at least) the first 2 years of life. ${ }^{28,39}$ Considering the significant effect of age on nutritional status, we included age in our models as a fixed factor to better understand the timing of growth faltering over ages and across the years of implementation of the UHC programs. Consistent with previous studies, we found higher prevalence of growth faltering and underweight, and more variability, during the first 2 years of life. Our findings support the current evidence that confirms the need to prioritize the first 1000 days of life. Interestingly, the empirical distributions of the prevalence of stunting and underweight for different years show almost parallel curves (with alike patterns; Figure 3; data available as a supplement to the online version of this article at http://www.ajph.org as Figure S10) that exhibit significant improvements in all ages during the 9-year period, justifying the model 1 specifications.

We analyzed data at national and regional levels, which have more homogeneous and representative coverage. At lower geographical levels of analysis, that is, province, department, and health center, we expected to find scattered prevalence and variable trends over the years, mostly because of local socioeconomic and cultural factors but also because of highly heterogeneous exposures to the programs; local variations in quality, the availability of collected information, and percentages of coverage are also important considerations.

A main limitation of our study was the lack of additional data at this stage to disaggregate the impacts of each program-UHC and conditional cash transfer-and to evaluate whether the improvements were related specifically to the interventions rather than a consequence of improved living conditions in the country as a whole.

In addition to the positive results regarding the prevalence of undernutrition, the implementation of these programs has facilitated the collection of substantial amounts of high-quality information, which has become an essential tool for guiding future strategies to reduce disparities and internal gaps in health care.

Universal health coverage is in a position to become a key instrument for enhancing health, social cohesion, sustainable development, and economic growth. ${ }^{40}$ Considering that vulnerable populations have higher levels of undernutrition, morbidity, and mortality rates, the implementation of these innovative strategies to improve health coverage and evidence-based interventions is a key focus of policymakers and planners aiming to improve child survival, health, and nutrition. Nevertheless, maintaining these strategies over time is essential for achieving sustained improvements in health-related indicators in the post-2015 sustainable development challenges. $A \mathrm{JPH}$

\section{CONTRIBUTORS}

P. A. Nuñez and D. Fernández-Slezak cleaned and curated data sources and designed and developed the database system. P. A. Nuñez, A. Farall, and M. E. Szretter assessed the data, developed statistical methods, and prepared the results. P. A. Nuñez, O.D. Salomón, and C. R. Valeggia designed the study concept and wrote the first draft of the article. D. Fernández-Slezak, A. Farall, and M. E. Szretter contributed to subsequent drafts of the article.

\section{ACKNOWLEDGMENTS}

This research was funded by Instituto Nacional de Medicina Tropical and Consejo Nacional de Investigaciones Científicas y Técnicas.

We gratefully acknowledge the assistance of Martín Sabignoso (national coordinator of universal health coverage programs) and the Área Planificación Estratégica e Investigación Aplicada Programa Sumar of the Argentina Ministry of Health, Cesar Victora for valuable comments on the article, and Mariela Sued for useful suggestions on statistical analysis.

P.A. Nuñez is responsible for the views expressed in this publication, which do not necessarily represent the views of the funding institutions and do not represent official statistics of the Argentina Ministry of Health.

\section{HUMAN PARTICIPANT PROTECTION}

No protocol approval was necessary because no human participants were involved in this study.

\section{REFERENCES}

1. Black RE, Allen LH, Bhutta ZA, et al. Maternal and child undernutrition: global and regional exposures and health consequences. Lancet. 2008;371(9608):243-260.

2. Caulfield LE, de Onis M, Blössner M, Black RE. Undernutrition as an underlying cause of child deaths associated with diarrhea, pneumonia, malaria, and measles. Am J Clin Nutr. 2004;80(1):193-198.

3. Victora CG, Adair L, Fall C, et al. Maternal and child undernutrition: consequences for adult health and human capital. Lancet. 2008;371(9609):340-357.

4. Black RE, Victora CG, Walker SP, et al. Maternal and child undernutrition and overweight in low-income 
and middle-income countries. Lancet. 2013;382(9890): 427-451.

5. Grantham-McGregor S, Cheung YB, Cueto S, Glewwe P, Richter L, Strupp B. Developmental potential in the first 5 years for children in developing countries. Lancet. 2007;369(9555):60-70.

6. World Health Organization. Physical status: the use and interpretation of anthropometry. Report of a WHO Expert Committee. World Health Organ Tech Rep Ser. 1995;854:1-452.

7. Atun R, de Andrade LO, Almeida G, et al. Healthsystem reform and universal health coverage in Latin America. Lancet. 2015;385(9974):1230-1247.

8 . Frenk J. Leading the way towards universal health coverage: a call to action. Lancet. 2015;385(9975): 1352-1358.

9. 4 World Bank. Argentina: provincial maternal and child health insurance. A results-based financing project at work. Available at: http://siteresources.worldbank.org/ INTLAC/Resources/En_Breve_Argentina_150.pdf. Accessed February 1, 2016.

10. Sabignoso M. A 10-year-old results-based financing experience (2004-2014). 2014. Available at: http:// es.slideshare.net/RBFHealth/3-01-plan-sumar-en. Accessed February 1, 2016

11. Economic Commission for Latin America and the Caribbean. Non-contributory social protection programmes in Latin America and the Caribbean database: conditional cash transfer programmes. 2013. Available at: http://dds.cepal.org/bdptc. Accessed February 1, 2016.

12. De Brauw A, Gilligan D, Hoddinott J, Roy S. The Impact of Bolsa Familia on Child, Maternal, and Household Welfare. Washington, DC: International Food Policy Research Institute; 2012.

13. Fernald LC, Gertler PJ, Neufeld LM. Role of cash in conditional cash transfer programmes for child health, growth, and development: an analysis of Mexico's Oportunidades. Lancet. 2008;371(9615):828-837.

14. Programa Familias en Acción. Impacto del Programa a un año y Medio de su Ejecución. Bogota, Colombia: Departamento Nacional de Planeación; 2006.

15. Boerma T, Eozenou P, Evans D, Evans T, Kieny MP, Wagstaff A. Monitoring progress towards universal health coverage at country and global levels. PLoS Med. 2014;11(9):e1001731.

16. de Andrade LO, Pellegrini Filho A, Solar O, et al. Social determinants of health, universal health coverage, and sustainable development: case studies from Latin American countries. Lancet. 2015;385(9975):1345-1351.

17. Manley J, Gitter S, Slavchevska V. How Effective Are Cash Transfer Programmes at Improving Nutritional Status? A Rapid Evidence Assessment of Programmes' Effects on Anthropometric Outcomes. London, UK: EPPI-Centre, Social Science Research Unit, Institute of Education, University of London; 2012.

18. Gertler P, Giovagnoli P, Martinez S. Rewarding Provider Performance to Enable a Healthy Start to Life: Evidence From Argentina's Plan Nacer. Washington, DC: World Bank; 2014.

19. WHO Child Growth Standards: Length/Height-for-Age, Weight-for-Age, Weight-for-Length, Weight-for-Height and Body Mass Index-for-Age: Methods and Development. Geneva, Switzerland: World Health Organization; 2006. 20. Cole TJ, Green PJ. Smoothing reference centile curves: the LMS method and penalized likelihood. Stat Med. 1992;11(10):1305-1319.
21. de Onis M, Blössner M, Borghi E. Global prevalence and trends of overweight and obesity among preschool children. Am J Clin Nutr. 2010;92(5):1257-1264.

22. R Development Core Team. R: a language and environment for statistical computing. 2011. Available at: http://www.R-project.org. Accessed February 1, 2016. 23. Bates D, Maechler M, Bolker B, et al. lme4: linear mixed-effects models using Eigen and S4. 2014. Available at: http://CRAN.R-project.org/package=lme4. Accessed February 1, 2016.

24. Pinheiro JC. Topics in Mixed-Effects Models $[\mathrm{PhD}$ dissertation]. Madison, WI: University of Wisconsin; 1994.

25. Pinheiro J, Bates D. Mixed-Effects Models in $S$ and S-PLUS. New York, NY: Springer-Verlag; 2000.

26. Leroy JL, Ruel M, Habicht JP, Frongillo EA. Linear growth deficit continues to accumulate beyond the first 1000 days in low- and middle-income countries: global evidence from 51 national surveys. $J$ Nutr. 2014; 144(9):1460-1466.

27. Victora CG, de Onis M, Shrimpton R. Linear growth faltering should be assessed in absolute and relative terms. J Nutr. 2014;144(12):2092-2093.

28. Prendergast AJ, Humphrey JH. The stunting syndrome in developing countries. Paediatr Int Child Health. 2014;34(4):250-265.

29. de Onis M, Blössner M, Borghi E. Prevalence and trends of stunting among pre-school children, 19902020. Public Health Nutr. 2012;15(1):142-148.

30. Stevens GA, Finucane MM, Paciorek CJ, et al. Trends in mild, moderate, and severe stunting and underweight, and progress towards MDG 1 in 141 developing countries: a systematic analysis of population representative data. Lancet. 2012;380(9844):824-834.

31. Repetto F, Potenza Dal Masetto F. Social Protection Systems in Latin America and the Caribbean: Argentina. Santiago, Chile: United Nations; 2011.

32. United Nations Development Programme. República Argentina: objetivos de desarrollo del milenio: rendición de cuentas 2010. 2010. Available at: http:// www.undp.org/content/dam/undp/library/MDG/ english/MDG\%20Country\%20Reports/Argentina/ rendicion_de_cuentas_2010_castellano_ingles.pdf. Accessed February 1, 2016.

33. Victora CG, Aquino EM, do Carmo Leal M, Monteiro CA, Barros FC, Szwarcwald CL. Maternal and child health in Brazil: progress and challenges. Lancet. 2011;377(9780):1863-1876.

34. Rasella D, Aquino R, Santos CA, Paes-Sousa R, Barreto ML. Effect of a conditional cash transfer programme on childhood mortality: a nationwide analysis of Brazilian municipalities. Lancet. 2013;382(9886):57-64.

35. Rivera JA. Improving nutrition in Mexico: the use of research for decision making. Nutr Rev. 2009;67(suppl 1): S62-S65.

36. Fotso JC. Child health inequities in developing countries: differences across urban and rural areas. Int $J$ Equity Health. 2006;5:9.

37. Van de Poel E, O'Donnell O, Van Doorslaer E. Are urban children really healthier? Evidence from 47 developing countries. Soc Sci Med. 2007;65(10): 1986-2003.

38. Paciorek CJ, Stevens GA, Finucane MM, Ezzati M; Nutrition Impact Model Study Group (Child Growth). Children's height and weight in rural and urban populations in low-income and middle-income countries: a systematic analysis of population-representative data. Lancet Glob Health. 2013;1(5):e300-e309.

39. Victora CG, de Onis M, Hallal PC, Blössner M, Shrimpton R. Worldwide timing of growth faltering: revisiting implications for interventions. Pediatrics. 2010; 125(3):e473-e480.

40. United Nations General Assembly. Adopting consensus text, General Assembly encourages member states to plan, pursue transition of national health care systems towards universal coverage. 2012. Available at: http://www.un.org/press/en/2012/ga11326.doc.htm. Accessed February 1, 2016 